\title{
FORECASTING WIND AND SOLAR ENERGY ON SHORT TIME SCALES
}

\author{
JING HUANG
}

(Received 24 September 2013; first published online 26 November 2013)

2010 Mathematics subject classification: primary 37M10; secondary 70G60.

Keywords and phrases: time series analysis, solar radiation forecasting, wind energy forecasting, Lucheroni model, CARDS model, direct normal irradiation (DNI), Boland-Ridley-Lauret (BRL) model.

Due to the ever increasing consumption of electricity and resulting deterioration of the environment, the use of renewable sources to generate electricity has drawn more and more attention. Solar and wind energy are widely utilised for generating electricity as the most promising renewable energy source in recent decades. However, because of the intermittent nature of sun and wind, there is great variability in using solar and wind energy to generate electricity, especially when weather conditions change dramatically, such as clouds blocking the sun and the wind suddenly dying down. This thesis introduces a new model, termed the coupled autoregressive and dynamical system (CARDS) model. It not only provides a high level of accuracy for onestep-ahead forecasts on short time scales of solar radiation or wind energy data but also offers a different perspective on forecasting solar or wind energy concentrated on individual locations, which is different from most models focusing on a global optimisation problem.

Solar radiation data at three different time scales from two different Australian locations has been used in the thesis and the results demonstrate that the CARDS model can effectively improve individual point forecasting, especially for high peak data points. The CARDS model has been used not only for solar radiation forecasting, but also for wind energy forecasting. The CARDS model overall shows better forecasting ability than an autoregressive model. The latter model is widely known as one of the best models for forecasting short term wind energy data.

In the case of resource assessment for either concentrating solar thermal or tracking photovoltaic systems, the thesis has also shown that it is not necessary to use a purposebuilt direct normal radiation model. The Boland-Ridley-Lauret global-to-diffuse

Thesis submitted to the University of South Australia; degree conferred 28 August 2013; principal supervisor: Professor John Boland.

(C) 2013 Australian Mathematical Publishing Association Inc. 0004-9727/2013 \$16.00 
model, followed by estimation of the direct normal, is sufficient. For the purpose of effectively improving the proportion of renewable energy and taking advantage of both wind and solar, the hybrid wind and solar system has also been investigated in the thesis. The result illustrates that using the hybrid wind and solar system can increase the stability of energy supply and accuracy of forecasting in comparison to a wind or solar energy system alone.

The papers [1-3] have arisen from this thesis.

\section{References}

[1] J. Boland, M. Korolkiewicz, M. Agrawal and J. Huang, 'Forecasting solar radiation on short time scales using a coupled autoregressive and dynamical system (CARDS) model', Proceedings of the Australian Solar Energy Conference, Melbourne, 6-7 December 2012.

[2] J. Boland, J. Huang and B. Ridley, 'Decomposing global solar radiation into its direct and diffuse components', Ren. Sus. Energy Rev. 28 (2013), 749-756.

[3] J. Huang, M. Korolkiewicz, M. Agrawal and J. Boland, 'Forecasting solar radiation on an hourly time scale using a Coupled AutoRegressive and Dynamical System (CARDS) model', Solar Energy 87 (2013), 136-149.

JING HUANG, School of Information Technology and Mathematical Sciences, University of South Australia, Mawson Lakes, South Australia 5095, Australia e-mail: jing.huang@unisa.edu.au 